Part of Journal of Research of the National Bureau of Standards, Volume 25, September 1940

\title{
DECOMPOSITION OF ROCKS AND CERAMIC MATERIALS WITH A SMALL AMOUNT OF SODIUM CARBONATE
}

\author{
By James I. Hoffman
}

ABSTRACT

A method for the decomposition of rocks and ceramic materials is presented in which only 2 parts of sodium carbonate are used for 1 part of sample. The fusion is made in a $75-\mathrm{ml}$ platinum dish instead of a crucible. If silica is to be determined, the same dish is used for the fusion, the disintegration of the melt with hydrochloric acid, the evaporation to dryness, and the ignition of the silica.

\section{CONTENTS}

I. Introduction

II. Method for the determination of silica

III. Discussion of the procedure and results

\section{INTRODUCTION}

For the decomposition of rocks and ceramic materials, fusion of 1 part of sample with 4 to 10 parts of sodium carbonate is usually recommended. The large amount of sodium salt thus introduced is often undesirable in the determinations which follow. The desirability of using smaller amounts of flux was recognized by Finn and Klekotka, ${ }^{1}$ who showed that certain ceramic materials, for example, clay, feldspar, and high-alumina refractories, can be successfully broken up by sintering at $825^{\circ}$ to $950^{\circ} \mathrm{C}$ with a portion of sodium carbonate approximately equal to the weight of the sample. Decomposition by sintering is satisfactory provided that the most suitable sintering temperature and quantity of sodium carbonate have been determined. In the method which follows, the quantity of flux and temperature of fusion are the same for all the materials.

The experiments on fusions with less than the customary amounts of sodium carbonate were started primarily to develop a method for determining the silica content of glass and of certain ceramic materials by a single dehydration. After many trials, it was found that satisfactory results could not be obtained by single dehydrations, ${ }^{2}$ but the

1 A. N. Finn and J. F. Klekotka, BS J. Research 4, 809 (1930) RP180.

2 The method which came closest to giving satisfactory results for silica in glass in one dehydration is one developed by P. A. Webster and A. K. Lyle of the Hartford-Empire Co., Hartford, Conn. (private communication). Their method is similar to the one described herein, except that nitric acid is used to decom. pose the fused mass and perchloric acid is used for the dehydration. Seldom does more than 0.1 percent of the silica remain in solution with their method, but it was found that no method, whentapplied to miscellaneous materials, is entirely dependable unless two dehydrations are made. [While this article was i n press Webster and Lyle's method appeared in J. Am. Ceram. Soc. 23, 235 (1940).] 
decomposition of the various materials was so successful that it seemed worth while to extend the study to a wider range of ceramic materials, and also to rocks and minerals.

Disintegration of the melt obtained with the method described in this paper leaves practically all the silica as a residue, whereas a clear or nearly clear solution is obtained by similarly treating a melt obtained by fusing with a large quantity of sodium carbonate. The results of this study indicate that the amount of nonvolatile matter retained by the insoluble mass that results from disintegration of the former melt is about equal to that which is adsorbed and retained by the gelatinous silicic acid which separates during the evaporation of the clear solution obtained from the latter melt. The fact that inspection does not immediately show whether decomposition has been complete when only a small amount of sodium carbonate has been used may account for the almost universal use of unnecessarily large quantities of flux. Furthermore, the earlier analysts did not have furnaces in which uniform temperatures of about $1,200^{\circ} \mathrm{C}$ could be maintained.

\section{METHOD FOR THE DETERMINATION OF SILICA}

Transfer $0.5000 \mathrm{~g}$ of the finely ground sample (60 mesh or finer) and $0.50 \mathrm{~g}$ of sodium carbonate to a $75-\mathrm{ml}$ platinum dish, ${ }^{3}$ and intimately mix the contents by means of the flattened end of a glass rod. If the sample contains ferrous iron or much lead, add $0.05 \mathrm{~g}$ of potassium nitrate to prevent alloying of the platinum dish. Brush the mixture into the center of the dish, flatten the charge so that it covers a space about $3 \mathrm{~cm}$ in diameter, and then cover it as evenly as possible with an additional $0.50 \mathrm{~g}$ of sodium carbonate. Heat gradually at first (preferably in a muffle furnace) and finally at $1,200^{\circ}$ $\mathrm{C}$ for 15 minutes. ${ }^{4}$ Remove the dish from the source of heat, and cover it to prevent loss of small pieces of the solidified melt that might be ejected during cooling.

Add $20 \mathrm{ml}$ of diluted hydrochloric acid $(1+1)^{5}$ to the cooled melt, cover the dish, and digest on the steambath until disintegration is complete. The action of the acid can be hastened by occasionally crushing the layer of insoluble silica that tends to cover the unattacked portion of the fused mass. As soon as disintegration is complete, crush all flakes of solid matter with the flattened end of a glass rod. Evaporate to dryness on the steambath, cool, drench the dry residue with $5 \mathrm{ml}$ of hydrochloric acid, and then add $15 \mathrm{ml}$ of warm water. Digest on the steambath for a few minutes, and filter through a 9-cm filter of loose texture (No. 40 Whatman or equivalent). Thoroughly wash the dish and filter paper with hot hydrochloric acid $(2+98)$,

\footnotetext{
${ }^{3}$ Dishes such as are used in determinations of alkalies are satisfactory. Part of this work was done with $50-\mathrm{ml}$ dishes made of platinum alloyed with about 2 percent of iridium. The remainder was done with special long-lipped 75-ml dishes of platinum alloyed with 3.5 percent of rhodium. The latter dishes, weighing about $40 \mathrm{~g}$, were preferable because they are not readily bent out of shape and because the solutions can be poured onto the filter more easily.

4 A temperature of $1,200^{\circ} \mathrm{C}$ is specified, but this may be regarded as a maximum because nothing is gained by heating to a higher temperature than that required to give a clear melt. Even at $1,200^{\circ} \mathrm{C}$, some highalumina refractories will yield only a sintered mass, not a clear melt. The decomposition, however, is complete.

5 This denotes 1 volume of concentrated hydrochloric acid, sp gr 1.18, diluted with 1 volume of water. Diluted hydrochloric acid $(2+98)$ denotes 2 volumes of hydrochloric acid, sp gr 1.18 , diluted with 98 volumes of water. If no dilution is specified, the concentrated reagent is meant.
} 
but make no attempt to transfer all the silica from the dish to the paper. Place the filter containing the silica in the platinum dish in which the fusion and dehydration were made, and evaporate the filtrate to dryness on the steambath in another dish, preferably of platinum. Cool, drench the dry residue from the filtrate with hydrochloric acid, dilute, filter, and wash as before. Transfer all the silica obtained in the second dehydration to the paper, and then place this paper also in the platinum dish in which the fusion was made.

Ignite the contents of the dish slowly at first and finally for $1 / 2$ to 1 hour at $1,200^{\circ} \mathrm{C}$. Cool in a desiccator and weigh. Treat the ignited residue with a few drops of diluted sulfuric acid $(1+1)$ and about 10 $\mathrm{ml}$ of hydrofluoric acid. Evaporate the volatile constituents on the steambath, drive off the sulfuric acid by heating over a free flame, and finally ignite the residue for 1 to 2 minutes at $1,200^{\circ} \mathrm{C}$. The difference between the first and second weights, with a proper correction for a blank for the reagents, represents the silica in the sample.

TABLE 1.-Typical results obtained for silica and " $\mathrm{R}_{2} \mathrm{O}_{3}$ " in various materials

\begin{tabular}{|c|c|c|c|c|c|c|}
\hline \multirow[b]{2}{*}{ No. } & \multirow[b]{2}{*}{ Material (0.5-g samples) } & \multicolumn{2}{|c|}{$\mathrm{SiO}_{2}$} & \multirow{2}{*}{$\begin{array}{l}\text { Nonvolatile } \\
\text { residue by } \\
\text { method } \\
\text { employing } \\
1 \mathrm{~g} \text { of } \\
\mathrm{Na}_{2} \mathrm{CO}_{3}\end{array}$} & \multicolumn{2}{|c|}{ " $\mathrm{R}_{2} \mathrm{O}_{3}$ " " } \\
\hline & & $\begin{array}{l}\text { By method } \\
\text { employing } \\
4 \text { to } 10 \mathrm{~g} \text { of } \\
\mathrm{Na}_{2} \mathrm{CO}_{3} \text { in } \\
\text { fusion }\end{array}$ & $\begin{array}{l}\text { By method } \\
\text { employing } \\
1 \mathrm{~g} \text { of } \\
\mathrm{Na}_{2} \mathrm{CO}_{3} \text { in } \\
\text { fusion }\end{array}$ & & $\begin{array}{l}\text { By method } \\
\text { employing } \\
4 \text { to } 10 \mathrm{~g} \text { of } \\
\mathrm{Na}_{2} \mathrm{CO}\end{array}$ & $\begin{array}{l}\text { By method } \\
\text { employing } \\
1 \mathrm{~g} \text { of } \\
\mathrm{Na}_{2} \mathrm{CO}_{3}\end{array}$ \\
\hline 1 & NBS Standard Feldspar 70 & $\begin{array}{l}\text { Percent } \\
\quad 66.66\end{array}$ & $\begin{array}{l}\text { Percent } \\
66.62\end{array}$ & $\begin{array}{l}g \\
0.0005\end{array}$ & $\begin{array}{c}\text { Percent } \\
18.07\end{array}$ & $\begin{array}{c}\text { Perzent } \\
18.08\end{array}$ \\
\hline 2 & NBS Standard Feldspar 70 - & 66. 66 & $\quad 66.70$ & .0010 & & \\
\hline 3 & NBS Burnt Refractory 76 & 54. 68 & 54.76 & .0059 & & 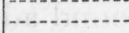 \\
\hline 4 & NBS Burnt Refractory 77. & 32. 38 & 32.34 & .0033 & & \\
\hline 5 & NBS Burnt Refractory 78 & 20.69 & 20.70 & .0098 & 74.92 & 74.84 \\
\hline 6 & $\begin{array}{l}\text { NBS Standard Glass } 128 \\
\text { NBS Standard Glass } 128\end{array}$ & 69. 51 & 69.46 & .0004 & 1.96 & 2.00 \\
\hline $\begin{array}{l}7 \\
8\end{array}$ & $\begin{array}{l}\text { NBS Standard Glass } 128 \\
\text { NBS Standard Flint Clay } 97\end{array}$ & $\begin{array}{l}69.51 \\
42.87\end{array}$ & $\begin{array}{l}69.56 \\
42.80\end{array}$ & .0005 & & \\
\hline 9 & Basalt (E. page 38) b....... & 57.87 & 57.98 & .0027 & & \\
\hline 10 & Keratophyre (G. page 31) & 72.73 & 72.62 & .0015 & 16.52 & 16.56 \\
\hline 11 & Quartz monzonite ( $\mathrm{C}-2$ page 12 and & & & & & \\
\hline 12 & $\begin{array}{l}\text { 13) } \\
\text { Reddish andesite }(\mathrm{F} \text {. page } 37)\end{array}$ & $\begin{array}{l}69.01 \\
55.18\end{array}$ & $\begin{array}{l}68.98 \\
55.12\end{array}$ & $\begin{array}{l}.0023 \\
.0029\end{array}$ & 18.88 & 18.90 \\
\hline 13 & Cyrtolite (Bedford, N. Y.) & 31.27 & 31.31 & .0207 & 55.54 & 55.58 \\
\hline 14 & Cyrtolite (Bedford, N. Y.) & 31.27 & - 31.34 & c. 0069 & 55.54 & 55.68 \\
\hline 15 & Chlorite (Vt.) & 25.22 & 25.24 & .0016 & & \\
\hline 16 & Granite (Alaska) & 73.12 & 73.20 & .0015 & & \\
\hline 17 & Hornblende. & 62.80 & 62.88 & .0016 & & \\
\hline 18 & Soil (Texas) d & 65. 66 & 65.74 & .0008 & 8.15 & 8.19 \\
\hline $\begin{array}{l}19 \\
20\end{array}$ & $\begin{array}{l}\text { Rhyolite } \\
\text { Miscellaneous samples of limestones }\end{array}$ & 74.72 & 74.88 & .0022 & & \\
\hline & $\begin{array}{l}\text { clays, quartz, lead-bearing glass, } \\
\text { and bauxite were completely de- } \\
\text { composed, but } \mathrm{SiO}_{2} \text { was not deter- } \\
\text { mined }\end{array}$ & & & & & \\
\hline 21 & $\begin{array}{l}\text { Alundum cement and } 120 \text {-mesh } R R \\
\text { Alundum were not satisfactorily } \\
\text { decomposed }\end{array}$ & & & & & \\
\hline
\end{tabular}

a " $\mathrm{K}_{2} \mathrm{O}_{3}$ " represents the total residue obtained by adding a slight excess of ammonium hydroxide to the filtrate obtained from the determination of silica, filtering, dissolving the precipitate in acid reprecipitating with ammonium hydroxide, and igniting to constant weight. The residue left after volatilizing the silica was fused, the melt was dissolved, and the solution added to the filtrate from the silica before the precipitation with ammonium hydroxide.

b The references following materials $9,10,11$, and 12 are the designations in U. S. Geological Survey Bulletin 878 , from which the values for $\mathrm{SiO}_{2}$ are taken and where complete analyses are given.

- Sulfuric acid dehydration.

d Other constituents of the soil from Texas are $\mathrm{CaO}, 7.11$ percent; $\mathrm{MgO}, 0.77$ percent; and $\mathrm{SO}_{3}, 8.59$ percent. 


\section{DISCUSSION OF THE PROCEDURE AND RESULTS}

Typical results obtained in the determination of silica and " $\mathrm{R}_{2} \mathrm{O}_{3}$ " are shown in table 1 . There is no particular advantage in fusing with the small amount of sodium carbonate for determining " $\mathrm{R}_{2} \mathrm{O}_{3}$ " if two precipitations with ammonium hydroxide are made, but these results are included for completeness and to show that the method can be used for this determination.

The use of the same platinum dish for the fusion of the sample, the disintegration of the melt, the evaporation to dryness, and the ignition of the silica approximately halves the time and labor required for a determination of silica and reduces the chances of losses that might occur in the transfer from one vessel to another. In fusing the materials listed in table 1, there was no frothing or spattering, and consequently no occasion for covering the dishes. This is the more surprising because some of the materials, for instance clay and bauxite, contain a considerable percentage of volatile matter.

The nonvolatile residues shown in table 1 are not abnormally large. In the analysis of high-alumina burnt refractories, such residues often weigh more than $5 \mathrm{mg}$, even if the usual large amount of sodium carbonate has been used in the fusion. Nonvolatile residues do not always indicate incomplete decomposition. They may result from incomplete solution of salts after dehydration of the silica, as is usual with materials high in alumina, or the material (for example, cyrtolite) may contain tantalum and columbium, both of which practically quantitatively accompany silica in any method. With materials such as burnt refractories (high in $\mathrm{Al}_{2} \mathrm{O}_{3}$ ) or cyrtolite (high in $\mathrm{ZrO}_{2}$ ), it was found advantageous to use sulfuric acid for the dehydrations, because the nonvolatile residues were always smaller.

The results in table 1 indicate also that this method of decomposition is applicable to many minerals and nearly all kinds of rocks and ceramic materials except fused alumina. With such alumina an increase of the temperature to $1,300^{\circ} \mathrm{C}$ does not effect complete decomposition, and attack on the platinum dishes becomes serious. By mixing 1 part of 90-mesh $R R$ Alundum with 1 part of sodium carbonate and 1 part of fused borax, and heating for 15 minutes at $1,200^{\circ} \mathrm{C}$, a melt was obtained which left an insoluble residue of only $1.3 \mathrm{mg}$ when the fused mass was treated with a mixture of hydrofluoric and hydrochloric acids. Such a fusion, however, is not satisfactory for the determination of silica because of serious contamination of the silica by boron. Ordinarily, boron can be eliminated by evaporation with methyl alcohol and hydrochloric acid, but when such a small amount of flux is used, disintegration of the melt with hydrochloric acid leaves the silica in rather hard flakes, from which the boron apparently cannot be removed by the usual treatment.

Fusions and ignitions in platinum dishes at $1,200^{\circ} \mathrm{C}$ always cause a loss of 1 to $2 \mathrm{mg}$ of platinum in a determination, but the dishes are never damaged unless reducing substances, such as ferrous iron, are present. The addition of potassium nitrate prevents damage from this source and is recommended if the material contains much lead ${ }^{6}$

6 Samples of lead-barium glass containing 17.5 percent of $\mathrm{PbO}$ were decomposed by heating to $1,200^{\circ} \mathrm{C}$ with the recommended amounts of sodium carbonate and potassium nitrate, without any damage to the dishes. 
or ferrous iron. The loss of platinum by volatilization does not affect the results for silica unless it occurs after the treatment with hydrofluoric and sulfuric acids. Owing to the relatively large surface of these dishes, as compared with crucibles, a long period of ignition at this point may result in high values for silica. For this reason a short period of ignition of the nonvolatile residue is recommended.

It is often desirable to precipitate iron, aluminum, calcium, and magnesium from solutions containing only small quantities of sodium salts, and it is probable that the method described will find application in other determinations in which large amounts of sodium salts are objectionable.

Acknowledgment is made to R. C. Wells and J. G. Fairchild, of the U. S. Geological Survey, who furnished many of the samples of rocks used in this work.

Washington, July 18, 1940. 